\title{
BIOMASSA MICROBIANA E MATÉRIA ORGÂNICA LEVE EM SOLOS SOB SISTEMAS AGRÍCOLAS ORGÂNICO E CONVENCIONAL NA CHAPADA DA IBIAPABA - $\mathrm{CE}^{(1)}$
}

\author{
Francisco Alisson da Silva Xavier ${ }^{(2)}$, Stoécio Malta Ferreira Maia ${ }^{(3)}$, \\ Teógenes Senna de Oliveira ${ }^{(4)}$ \& Eduardo de Sá Mendonça ${ }^{(5)}$
}

\begin{abstract}
RESUMO
Em muitos casos, a substituição da vegetação nativa por sistemas agrícolas resulta em decréscimo nos conteúdos de $\mathrm{C}$ e $\mathrm{N}$ nos diferentes compartimentos da matéria orgânica do solo. Para testar se as práticas de manejo que priorizam o aporte de resíduos orgânicos promovem aumento dos compartimentos da matéria orgânica mais sensíveis ao manejo, este estudo se propôs estudar áreas de uma propriedade que utiliza um sistema de produção de acerola em larga escala, sob manejo orgânico, e uma área sob cultivo convencional de cenoura e beterraba em rotação com milho, pertencentes à Fazenda Amway Nutrilite do Brasil e à Associação de Horticultores do Pivot Central, respectivamente, ambas localizadas na região da Chapada da Ibiapaba, Ceará. Selecionou-se, também, uma área de pastagem localizada no interior da primeira propriedade amostrada, bem como áreas sob mata nativa, próximas às áreas de cultivo. Amostras de um Neossolo Quartzarênico foram coletadas nas profundidades de 0-5 e 5-15 cm e foram determinados os teores de C orgânico total, de C e $\mathrm{N}$ microbiano (Cmic e Nmic) e da matéria orgânica leve (Cmol e $\mathrm{Nmol}$ ), além do $\mathrm{C}$ mineralizável obtido por respirometria. O acúmulo médio nos estoques de Nmic nas áreas sob manejo orgânico em relação à mata nativa foi de $11,7 \mathrm{~kg} \mathrm{ha}^{-1}$, o que representou um incremento de 585 \% de Nmic nas áreas de cultivo. Já na pastagem, ocorreu acúmulo de $211 \mathrm{~kg} \mathrm{ha}^{-1}$ no estoque de Cmic em relação à mata nativa em subsuperfície, representando um incremento de $514,6 \%$. Por outro lado, os
\end{abstract}

\footnotetext{
(1) Parte da Tese de Mestrado do primeiro autor, apresentada ao Departamento de Ciências do Solo da Universidade Federal do Ceará - UFC. Recebido para publicação em setembro de 2004 e aprovado em março de 2006.

${ }^{(2)}$ Doutorando do Departamento de Solos, Universidade Federal de Viçosa - UFV. CEP 36570-000 Viçosa (MG). E-mail: ali_xavier@yahoo.com.br

${ }^{(3)}$ Doutorando do Departamento de Solos e Nutrição de Plantas, Escola Superior de Agricultura Luiz de Queiroz - ESALQ/USP. Av. Pádua Dias 11, CEP 13418-900 Piracicaba (SP). E-mail: stoecio@hotmail.com

(4) Professor Adjunto do Departamento de Ciências do Solo, Universidade Federal do Ceará- UFC. Campus do PICI, Bloco 807, CEP 60455-760 Fortaleza (CE). Bolsista do CNPq. E-mail: teo@ufc.br

(5) Professor do Departamento de Solos, UFV. Bolsista do CNPq. E-mail: esm@ufv.br
} 
estoques de Cmic no cultivo convencional sofreram reduções de 59 e $53 \%$, nas camadas de 0-5 e de 5-15 cm, respectivamente, em relação à mata nativa. Os estoques de Cmol obtidos nas linhas de cultivo nos sistemas orgânicos apresentaram incremento de $106 \%$, na camada de 0-5 cm, em relação à mata; no sistema convencional, porém, constatou-se uma redução em 31 \% no estoque de Cmol na camada superficial. Os resultados indicaram que o manejo realizado nas áreas sob cultivo orgânico com acerola e pastagem contribuiu para a manutenção e recuperação dos conteúdos de $\mathrm{C}$ e $\mathrm{N}$ da biomassa microbiana (BMS) e da matéria orgânica leve (MOL) do solo. Os incrementos e, ou, reduções de C e N nos compartimentos BMS e MOL, comparativamente à área nativa de referência, foram proporcionalmente maiores que os valores obtidos, quando considerados somente os estoques de $\mathrm{C}$ orgânico e $\mathrm{N}$ totais, principalmente na área sob sistema de cultivo convencional. Isto indica serem tais compartimentos sensíveis às mudanças no estado da matéria orgânica de acordo com o manejo. Os sistemas de manejo orgânico e pastagem constituem estratégias de manejo importantes que devem ser consideradas para a conservação e, ou, aumento da matéria orgânica e, conseqüentemente, para a melhoria da qualidade do solo e implementação do seqüestro de C na região da Chapada da Ibiapaba, Ceará.

Termos de indexação: agricultura biodinâmica, pastagem, C mineralizável, adubação verde, qualidade do solo, sustentabilidade.

\title{
SUMMARY: MICROBIAL BIOMASS AND LIGHT ORGANIC MATTER IN SOILS UNDER ORGANIC AND CONVENTIONAL SYSTEMS IN THE CHAPADA DA IBIAPABA - CE, BRAZIL
}

\begin{abstract}
Several studies reveal that the substitution of native vegetation by agricultural systems results in decreases in the $C$ and $N$ soil organic matter pools. Aiming to test the hypothesis that management practices favoring organic residue inputs promote increases in the most sensitive organic matter pools, the present study intended to study areas of an organic management system of acerola fruit production and a conventional cultivation area cropped with carrot and beet in crop rotation with corn. These areas belong to the Farm Amway Nutrilite do Brasil and Central Pivot Farmers Association, respectively, both in the Chapada da Ibiapaba, Ceará State, Brazil. A pasture area on the former was also selected. Areas under native forest, located near the cultivation areas, were sampled. Samples of a Quartzipsamment soil were collected from the depths $0-5$ and 5-15 cm. The total soil organic $C$, microbial $C$ and $N$ (Cmic and $\mathrm{Nmic}$ ), light organic matter $\mathrm{C}$ and $\mathrm{N}$ (Cmol and Nmol) and the mineralizable $\mathrm{C}$ were determined. An accumulation of $0.0117 \mathrm{Mg} \mathrm{ha}^{-1}$ was observed in the Nmic stock in the organic system soil in comparison to the native forest's, representing an increase of $585 \%$ in the Nmic stock. In addition, there was an accumulation of $0.211 \mathrm{Mg} \mathrm{ha}^{-1}$ in the Cmic stock in the pasture area, which represented an increase of $514.6 \%$ in these pools. On the other hand, Cmic stocks in the conventional system were reduced by 59 and $53 \%$ in the $0-5$ and 5-15 cm layers, respectively, in relation to the native forest. In the upper soil layer, the organic systems presented an increment of $106 \%$ in the Cmol stocks, while in the conventional system a reduction of $31 \%$ was observed in the same organic matter pool. The results obtained demonstrated that soil management in the areas under organic cultivation with acerola fruit and pasture contributed to the maintenance and recovery of the $C$ and $N$ microbial biomass and the light organic matter contents. The increments and/or reductions of $C$ and $N$ in the $M B$ and LOM pools, compared to the native forest, were proportionally larger than those of the total organic $C$ and $N$ stocks, mainly in the area under conventional system cultivation. This observation indicates that these compartments can be considered sensitive indicators of soil management alterations. In conclusion, the organic management systems and pasture areas represent important management strategies that should be considered for the conservation and/or increase of the soil organic matter and, consequently, for the improvement of the soil quality and C sequestration in the Chapada da Ibiapaba region.
\end{abstract}

Index terms: biodynamic agriculture, pasture, mineralizable $C$, green manure, soil quality, sustainability. 


\section{INTRODUÇÃO}

A matéria orgânica do solo (MOS) é considerada uma das principais fontes de energia e nutrientes ao sistema, capaz de manter a produtividade dos solos em geral. Dentre outros benefícios gerados pela MOS, destacam-se a melhoria das condições físicas do solo e o fornecimento de energia para o crescimento microbiano (Silva \& Resck, 1997), o que reflete em maior ciclagem de nutrientes e aumento da CTC do solo (Paes et al., 1996). Estes e outros benefícios conferem à MOS um papel fundamental na avaliação da qualidade do solo (Mielniczuk et al., 2003).

Estudos recentes revelam que a substituição da vegetação nativa por sistemas agrícolas cultivados resulta no decréscimo do aporte de $\mathrm{C}$ nos diferentes compartimentos da MOS (Marchiori Junior \& Melo, 2000; Leite et al., 2003). Tais perdas decorrem, em grande parte, do tipo de sistema de manejo adotado nas mais diversas condições de ambiente.

Nesse contexto, os sistemas agrícolas convencionais, caracterizados pelo intenso revolvimento do solo e pelo uso de elevadas quantidades de adubos químicos e pesticidas, contribuem, mais intensamente, para as perdas de C orgânico do solo (Rasmussen et al., 1998; Mielniczuk et al., 2003). Dessa forma, desenvolvese o processo de degradação química, física e biológica do solo, tendo como produto a redução de produtividade das culturas exploradas, cada vez mais acentuada com o manejo inadequado e o uso contínuo do solo.

Por outro lado, tem-se aumentado o interesse em avaliar os efeitos das opções de manejo com práticas conservacionistas que priorizem o aporte de MOS (Corea, 1998; Bayer et al., 2000; Marin, 2002; Leite et al., 2003). Segundo tais estudos, o manejo menos intensivo do solo promoveu acréscimos consideráveis no conteúdo total de $\mathrm{C}$ no solo e teve ação efetiva nas variações dos diferentes compartimentos da MOS. Nesse sentido, torna-se de fundamental importância a avaliação dos indicadores mais sensíveis às práticas de manejo, visando ao monitoramento dos impactos positivos ou negativos sobre o solo.

Estudos têm demonstrado que determinados compartimentos da MOS são capazes de detectar, mais rapidamente, as mudanças nos conteúdos de $\mathrm{C}$ no solo associadas ao manejo. As reduções nestes compartimentos são, de modo geral, maiores que as observadas, quando se considera apenas o conteúdo total de C do solo (Janzen et al., 1992). Numa escala crescente de sensibilidade, obtém-se, em primeira ordem, a biomassa microbiana do solo (BMS), bastante variável e sensível, considerada como compartimento ativo na dinâmica da MOS (Lundquist, et al., 1999); em seguida, representando uma medida de sensibilidade intermediária, obter-se-ia a matéria orgânica leve (MOL) (Freixo et al., 2002).
O objetivo do presente estudo foi testar a hipótese de que práticas de manejo que priorizam o aporte orgânico promovem alterações no compartimento ativo e lento da MOS, representado pela biomassa microbiana e pela matéria orgânica leve, respectivamente, permitindo considerá-los sensíveis ao manejo e promotores das melhorias da qualidade do solo.

\section{MATERIAL E MÉTODOS}

\section{Localização e descrição geral das áreas de estudo}

As áreas de estudo localizam-se na região da Chapada da Ibiapaba, situadas no km 334 da BR 220 no município de Ubajara-CE (latitude $3^{\circ} 51$ ' 12 ” S e longitude $41^{\circ} 5$ ' 10 ” W). O clima é o Amw' (tropical chuvoso de monção), segundo classificação de Köppen. A temperatura média anual da região é de $28^{\circ} \mathrm{C}$ e a precipitação média de $640 \mathrm{~mm}$ ano ${ }^{-1}$, com período chuvoso concentrando-se entre os meses de janeiro a maio, e o período seco geralmente estendendo-se de julho a novembro.

Em setembro de 2002, foram coletadas amostras de um Neossolo Quartzarênico das áreas pertencentes à Fazenda Amway Nutrilite do Brasil e à Associação dos Horticultores do Pivot Central. Na primeira propriedade, desenvolveu-se a produção de frutos de acerola em grande escala e em bases orgânicas, encontrando-se, atualmente, no segundo ano de conversão para sistema de produção biodinâmico. A segunda área de coleta selecionada foi caracterizada por um sistema de cultivo intensivo com cerca de 15 anos consecutivos de uso agrícola com utilização de pivot central, cujas principais culturas exploradas, até então, foram batata, feijão, cenoura e milho.

Foram selecionadas e amostradas as seguintes áreas:

Área 1: Área sob cultivo orgânico, estabelecida entre os meses de julho a dezembro de 1998, com aproximadamente 40 ha sob cultivo de acerola. Nos anos de 1991 a 1997, esta área foi cultivada com morango e melancia sob cultivo convencional. Antes do plantio de acerola, foi semeado coquetel de leguminosas/gramíneas (Quadro 1), seguido de sua incorporação, totalizando um conteúdo de massa verde incorporada de $45 \mathrm{t} \mathrm{ha}^{-1}$.

Utilizaram-se $1,7 \mathrm{t} \mathrm{ha}^{-1}$ de calcário dolomítico na correção do solo, $500 \mathrm{~kg} \mathrm{ha}^{-1}$ de fosfato natural e $300 \mathrm{~kg} \mathrm{ha}^{-1}$ de gesso agrícola. A calagem foi feita anualmente com base na análise do solo. Na ocasião do plantio da acerola, adicionaram-se $200 \mathrm{~g}$ de fosfato natural por cova. A adubação orgânica foi realizada por meio da adição de $22 \mathrm{~kg}$ de composto orgânico por planta aplicado na linha, duas vezes ao ano, num intervalo de seis meses, totalizando um 
aporte de aproximadamente $25 \mathrm{t} \mathrm{ha}^{-1} \mathrm{ano}^{-1}$. A composição e a caracterização química do composto orgânico encontram-se no quadro 2.

Aplicou-se bagana de carnaúba como cobertura morta nas linhas nos dois primeiros anos de cultivo. Nas entrelinhas, no início do período chuvoso, foram semeados calopogônio, soja perene e capim-bulfel, na proporção de $2 \mathrm{~kg} \mathrm{ha}^{-1}$ de semente. Antes da floração dessas espécies, realizou-se um roço mecânico nas entrelinhas incorporando a massa verde nas linhas. Utilizou-se sistema de irrigação tipo microaspersão com vazão de $22 \mathrm{~L} \mathrm{~h}^{-1}$. A coleta das amostras de solo nesta área foi realizada nas linhas e entrelinhas para a avaliação comparativa das duas condições: área de acerola com coquetel e por coleta nas linhas $\left(\mathrm{ACC}_{\mathrm{L}}\right)$ e nas entrelinhas $\left(\mathrm{ACC}_{\mathrm{E}}\right)$, respectivamente.

Área 2: Esta área está localizada ao lado da anteriormente descrita, tendo sido estabelecida também em dezembro de 1998. De forma similar à anterior, este talhão foi composto de quatro quadras de acerola com dimensão total de 40 ha. O histórico e o manejo nas linhas e entrelinhas desta área mostraram-se semelhantes aos da Área 1, no entanto, este talhão diferenciou-se por não ter recebido a incorporação do coquetel de leguminosas/ gramíneas. De modo semelhante à área anterior, a amostragem foi realizada nas linhas e entrelinhas sendo denominadas: área sem coquetel e por coleta, nas linha $\left(\mathrm{ASC}_{\mathrm{L}}\right)$ e nas entrelinhas $\left(\mathrm{ASC}_{\mathrm{E}}\right)$, respectivamente.

Área 3: Área de pastagem para criação de gado (PAST) com taxa de lotação de 0,5 animal ha-1. Imediatamente após a retirada da vegetação nativa,

Quadro 1. Composição e quantidades de sementes das espécies utilizadas no coquetel incorporado ao solo na Fazenda Amway Nutrilite do Brasil, no município de Ubajara-CE

\begin{tabular}{lc}
\hline Leguminosa/gramínea & Quantidade \\
& $\mathrm{kg} \mathrm{ha}^{-1}$ \\
Milho & 24,0 \\
Feijão-de-porco & 16,0 \\
Girassol & 8,0 \\
Mamona & 5,0 \\
Calopogônio & 4,0 \\
Milheto & 2,0 \\
Crotalária juncea & 10,0 \\
Crotalária spectabilis & 10,0 \\
Mucuna & 16,0 \\
Feijão-guandu & 16,0 \\
Lab Lab & 12,0 \\
Sorgo & 3,0 \\
Feijão-moita & 12,0 \\
\hline
\end{tabular}

Fonte: Fazenda Amway Nutrilite do Brasil.
Quadro 2. Composição e caracterização química do composto orgânico aplicado na linha de cultivo de acerola na Fazenda Amway Nutrilite do Brasil, no município de Ubajara-CE

\begin{tabular}{lc}
\hline Natureza do material(1) & $\begin{array}{c}\text { Proporção no conteúdo } \\
\text { total de composto } \\
\text { produzido em \% }\end{array}$ \\
\hline Bagaço de cana & 32,78 \\
Resíduo de acerola & 5,46 \\
Esterco de gado & 19,05 \\
Esterco de galinha & 8,60 \\
MB4(2) & 3,07 \\
Fosfato & 1,02 \\
Água & 30,00 \\
Caracterização química & \\
Nitrogênio $\left(\mathrm{g} \mathrm{kg}^{-1}\right)$ & \\
Potássio $\left(\mathrm{g} \mathrm{kg}^{-1}\right)$ & 22,00 \\
Cálcio $\left(\mathrm{g} \mathrm{kg}^{-1}\right)$ & 5,00 \\
Magnésio $\left(\mathrm{g} \mathrm{kg}^{-1}\right)$ & 40,00 \\
Enxofre $\left(\mathrm{g} \mathrm{kg}^{-1}\right)$ & 9,70 \\
Sódio (g kg-1) & 10,20 \\
Fósforo (g kg-1) & 6,20 \\
Ferro (g kg-1) & 23,40 \\
Manganês (g kg-1) & 31,00 \\
Cobre (g kg-1) & 0,52 \\
Zinco (g kg-1) & 0,03 \\
Boro (g kg-1) & 0,13 \\
Matéria orgânica (\%) & 0,10 \\
Relação C/N & 38,49 \\
\hline Fonte: Fazenda Amway Nutrilite do Brasil. & $(2)$ Fertilizante \\
natural derivado de rochas silicatadas. &
\end{tabular}
natural derivado de rochas silicatadas.

esta área foi cultivada em bases intensivas durante os anos de 1994 e 1995 com maracujá. Posteriormente, esteve sob pousio durante os anos de 1996 a 2001. O preparo do solo foi realizado em 2001 por meio de roço mecânico seguido de gradagem pesada. A calagem foi feita com a utilização de $1,7 \mathrm{t} \mathrm{ha}^{-1}$ de calcário dolomítico. Foram aplicados ainda $500 \mathrm{~kg} \mathrm{ha}{ }^{-1}$ de fosfato natural junto à semente e $300 \mathrm{~kg} \mathrm{ha}^{-1}$ de gesso agrícola. A semeadura foi realizada 3-4 meses após o preparo da área, ocasião em que foram utilizadas as seguintes espécies: Brachiaria decumbes, Brachiaria brizantha e Brachiaria ruziziensis na quantidade de 7-8 $\mathrm{kg} \mathrm{ha}^{-1}$ de semente para cada espécie. Anualmente, realizase um roço mecânico no início do período chuvoso.

Área 4: Área pertencente à Associação dos Horticultores do Pivô Central, representando uma situação de manejo intensivo do solo, com utilização de sistema de irrigação por pivot central. A partir do ano de 1985 até 1994, a área foi cultivada convencionalmente com olerícolas em rotação com feijão e milho. Já entre os anos de 1994 e 1997, não foi realizada nenhuma atividade agrícola, e, somente 
a partir de 1998, estendendo-se até 2002 , cultivouse cenoura em rotação com milho sob cultivo convencional (SCC). No preparo do solo, utilizou-se subsolador seguido de grade aradora e sulcador. A adubação química foi efetuada por meio da formulação NPK 6-24-12 na quantidade de $1.500 \mathrm{~kg} \mathrm{ha}^{-1}$. Realizou-se o controle de plantas espontâneas pela aplicação de herbicida à base de Linuron, conhecido comercialmente por Afalon, com dosagem de $2,5 \mathrm{~L} \mathrm{ha}^{-1}$.

Foram também selecionadas áreas sob mata nativa, localizadas próximas às áreas de estudos, sem qualquer tipo de interferência antrópica. A vegetação nativa, denominada de carrasco, é caracterizada pela ocorrência de indivíduos de baixo porte (3-4 m), constituída por espécies próprias e por outras oriundas de outras formações geograficamente próximas, como a floresta, o cerrado e a caatinga, apresentando alta densidade dos indivíduos lenhosos, os quais apresentam troncos finos e são uniestratificados. Maior detalhamento acerca desta vegetação pode ser observado no estudo de Araújo et al. (1999). As áreas de mata nativa referentes às áreas orgânicas e ao cultivo convencional foram representadas por MNo e MNc, respectivamente, e utilizadas como referencial no estudo comparativo às alterações promovidas pelo manejo do solo.

\section{Amostragem e características analisadas}

As amostras de solo foram coletadas nas profundidades de $0-2,2-5,5-10,10-15 \mathrm{~cm}$. A amostragem consistiu na abertura de pequenas trincheiras nas áreas selecionadas, totalizando um número de quatro repetições. Com base na análise de C orgânico total, uniram-se as camadas de 0-2 e $2-5 \mathrm{~cm}$, e de 5-10 e 10-15 cm, respectivamente, originando as camadas que foram efetivamente estudadas, ou seja, de $0-5$ e $5-15 \mathrm{~cm}$.

O CO total do solo (COT) foi quantificado por oxidação da matéria orgânica via úmida, empregando solução de dicromato de potássio $\left(\mathrm{K}_{2} \mathrm{Cr}_{2} \mathrm{O}_{7}\right)$ em meio ácido, com fonte externa de calor (Yeomans \& Bremner, 1988). O nitrogênio total (NT) foi quantificado por meio de digestão sulfúrica, seguida de destilação Kjeldahl, conforme Tedesco et al. (1995).

O C microbiano (Cmic) foi determinado pelo método da irradiação-extração, utilizando o forno microondas modelo Panasonic de potência igual a $900 \mathrm{~W}$ e freqüência de $2.450 \mathrm{MHz}$, conforme método descrito por Islam \& Weil (1998) e Ferreira et al. (1999). O extrator utilizado foi $\mathrm{K}_{2} \mathrm{SO}_{4} 0,5 \mathrm{~mol} \mathrm{~L}^{-1} \mathrm{e}$ o $\mathrm{C}$ contido nos extratos foi quantificado por meio de oxidação via úmida (Yeomans \& Bremner, 1998) sem aquecimento externo. O fator de conversão (Kc) usado para converter o fluxo de $\mathrm{C}$ para $\mathrm{C}$ da biomassa microbiana foi de 0,33 (Sparling \& West, 1988). Os teores de Cmic foram expressos com base na massa de solo seco em estufa a $105^{\circ} \mathrm{C}$, por $24 \mathrm{~h}$.

Para determinar o $\mathrm{N}$ microbiano (Nmic), as amostras de solo foram primeiramente acondicionadas em frascos plásticos e incubadas aerobicamente durante 21 dias, a fim de estimular a atividade microbiana, sendo a umidade mantida em $60 \%$ da capacidade de campo. Ao final do período de incubação do solo, determinou-se o Nmic por meio do método de irradiação e extração, utilizando-se o forno microondas modelo Cônsul de potência igual a $900 \mathrm{~W}$, conforme Islam \& Weil (1998). O extrator utilizado foi o $\mathrm{K}_{2} \mathrm{SO}_{4} 0,5 \mathrm{~mol} \mathrm{~L}^{-1}$ e o $\mathrm{N}$ contido nos extratos foi quantificado por meio de digestão sulfúrica, seguida de destilação Kjeldahl, conforme Tedesco et al. (1995). O fator de conversão $\left(K_{N}\right)$ utilizado para converter o fluxo de $\mathrm{N}$ em $\mathrm{N}$ da biomassa microbiana foi de 0,54 (Brookes et al., 1985). Os teores de Nmic foram expressos com base na massa de solo seco em estufa a $105{ }^{\circ} \mathrm{C}$ por $24 \mathrm{~h}$.

A atividade microbiana foi medida pela quantificação do $\mathrm{C}$ mineralizável, por meio do desprendimento do $\mathrm{CO}_{2}\left(\mathrm{C}-\mathrm{CO}_{2}\right)$, capturado em solução de $\mathrm{NaOH} 0,5 \mathrm{~mol} \mathrm{~L}^{-1}$, segundo método adaptado de Anderson (1982). As quantificações de $\mathrm{C}-\mathrm{CO}_{2}$ foram realizadas em intervalos de $2,5,10$, 15, 20, 25 e 30 dias. A curva de liberação de $\mathrm{CO}_{2}$ foi determinada, relacionando-se a produção acumulada de $\mathrm{C}-\mathrm{CO}_{2}$ com o tempo de incubação por meio de regressão.

A taxa de respiração por unidade de biomassa, ou quociente metabólico $\left(\mathrm{qCO}_{2}\right)$, foi obtida pela relação entre a taxa de respiração basal, que consiste na medida da produção de $\mathrm{CO}_{2}$, resultante da atividade metabólica no solo, e da biomassa microbiana (Anderson \& Domsch, 1985).

A matéria orgânica leve-livre (MOL) foi determinada por flotação em solução de iodeto de sódio $(\mathrm{NaI})$, densidade de $1,8 \mathrm{~kg} \mathrm{~L}^{-1}$. O material obtido foi seco $\mathrm{a} \pm 65^{\circ} \mathrm{C}$ e, posteriormente, pesado. Os teores de $\mathrm{C}$ e $\mathrm{N}$ da $\mathrm{MOL}$ (Cmol e $\mathrm{Nmol}$ ) foram quantificados por combustão via seca em analisador elementar Perkin Elmer CHNS/O 2400 (Sohi et al., 2001).

Os estoques de $\mathrm{C}$ e $\mathrm{N}$ foram calculados pela expressão: $\mathrm{C}$ ou $\mathrm{N}\left(\mathrm{t} \mathrm{ha}^{-1}\right)=$ teor $\left(\mathrm{g} \mathrm{kg}^{-1}\right)$ * densidade do solo $\left(\mathrm{kg} \mathrm{dm}^{-3}\right) *$ espessura da camada de solo $(\mathrm{dm})$.

\section{Análise estatística}

As comparações envolvendo os sistemas de manejo e as áreas sob vegetação nativa foram obtidas por meio de contrastes ortogonais originados a partir do desdobramento dos sete graus de liberdade para tratamento (Quadro 3). A significância dos contrastes com um grau de liberdade foi testada pelo teste $\mathrm{F}(\mathrm{P}<0,05$ e 0,01$)$ contra o quadrado médio do resíduo obtido pela análise de variância em delineamento inteiramente casualizado. 
Quadro 3. Contrastes ortogonais (C) utilizados na comparação entre os diferentes sistemas de manejo

\begin{tabular}{lrrrrrrr}
\hline Sistema & C1 & C2 & C3 & C4 & C5 & C6 & C7 \\
\hline ACC $_{E}$ & 1 & 0 & 1 & 1 & 1 & 0 & 0 \\
ACC $_{L}$ & 0 & 1 & -1 & 1 & 1 & 0 & 0 \\
ASC $_{E}$ & -1 & 0 & 1 & 1 & 1 & 0 & 0 \\
ASC $_{\mathrm{L}}$ & 0 & -1 & -1 & 1 & 1 & 0 & 0 \\
PAST & 0 & 0 & 0 & 0 & -4 & 1 & 0 \\
MNo & 0 & 0 & 0 & -4 & 0 & -1 & 0 \\
SCC & 0 & 0 & 0 & 0 & 0 & 0 & 1 \\
MNc & 0 & 0 & 0 & 0 & 0 & 0 & -1 \\
\hline
\end{tabular}

$\mathrm{ACC}_{\mathrm{E}}$ : área de acerola com coquetel com coleta de solo na entrelinha; $\mathrm{ACC}_{\mathrm{L}}$ : área de acerola com coquetel com coleta de solo na linha; $\mathrm{ASC}_{\mathrm{E}}$ : área de acerola sem coquetel com coleta de solo na entrelinha; $\mathrm{ASC}_{\mathrm{L}}$ : área de acerola sem coquetel com coleta de solo na linha; PAST: pastagem; MNo: área mata nativa referente às áreas orgânicas com acerola e pastagem; SCC: sistema de cultivo convencional; MNc: área de mata nativa referente ao sistema de cultivo convencional.

Os contrastes ortogonais $\mathrm{C} 1$ e $\mathrm{C} 2$ tiveram por objetivo avaliar o efeito do coquetel nas condições de coletas realizadas nas linhas e entrelinhas entre as áreas de cultivo orgânico. Já o contraste C3 propôs avaliar o manejo empregado nas linhas e entrelinhas, independentemente da incorporação do coquetel. As áreas sob cultivo orgânico foram avaliadas comparativamente à área sob vegetação nativa por meio do contraste $\mathrm{C} 4$. A área de pastagem foi comparada às áreas orgânicas e à área nativa por meio dos contrastes C5 e C6, respectivamente. $\mathrm{O}$ contraste $\mathrm{C} 7$ permitiu avaliar o sistema de cultivo convencional em relação à sua respectiva área de mata nativa.

Realizaram-se análises de regressão para obtenção das curvas que indicam as quantidades acumuladas de $\mathrm{C}-\mathrm{CO}_{2}$ liberadas de acordo com o tempo de incubação do solo dentro de cada sistema de manejo.

\section{RESULTADOS E DISCUSSÃO}

\section{Biomassa microbiana do solo}

O uso do coquetel de leguminosas/gramíneas não acarretou aumentos nos teores de $\mathrm{C}$ e $\mathrm{N}$ microbiano (Cmic e Nmic) nas áreas sob cultivo orgânico (Quadro 4, C1 e C2). Este resultado indica que a biomassa produzida pelo coquetel foi consumida em curto prazo, razão pela qual as diferenças entre efeitos das duas situações não puderam ser detectadas após seis anos da época de incorporação.

Os teores de Cmic obtidos nas linhas foram superiores aos observados nas entrelinhas na profundidade de $0-5 \mathrm{~cm}$, o que pode ter sido influenciado pela disponibilidade do substrato orgânico nas linhas. Entretanto, o mesmo não foi observado para os teores de Nmic (Quadro 4, C3).

Os teores de Cmic obtidos nas áreas de cultivo orgânico não diferiram dos teores obtidos na área sob vegetação nativa (Quadro 4, C4). Não é comum observar que sistemas de cultivo apresentem conteúdos semelhantes, ou maiores, de Cmic comparativamente a um ambiente natural, desde que este esteja equilibrado (Marchiori Jr. \& Melo, 1999; D’Andréa et al., 2002; Leite et al., 2003). Partindo do princípio de que a biomassa microbiana é um compartimento regulado pela disponibilidade de substrato orgânico (Souza \& Melo, 2000), a baixa produção de biomassa vegetal na área nativa, aproximadamente de $15 \mathrm{t} \mathrm{ha}^{-1} \mathrm{ano}^{-1}$, cuja proporção é $40 \%$ inferior ao que é adicionado nas áreas orgânicas, pode explicar os valores similares de Cmic nesta área em relação aos sistemas de cultivo orgânicos. Em adição, a melhor condição de umidade nas áreas cultivadas é outro fator preponderante que favorece o crescimento microbiano.

Os teores de Nmic nas áreas de cultivo orgânico foram superiores aos obtidos na área sob mata nativa na camada de 0-5 cm (Quadro 4, C4), possivelmente em resposta à adição do composto orgânico e à fixação de $\mathrm{N}$ propiciada por espécies de leguminosas plantadas nas entrelinhas. O acúmulo médio nos estoques de Nmic nas áreas sob manejo orgânico em relação à mata nativa $\left(2 \mathrm{~kg} \mathrm{ha}^{-1}\right)$ foi de $11,7 \mathrm{~kg} \mathrm{ha}^{-1}$ (Quadro 4), o que representou um incremento de $585 \%$ nos estoques de Nmic em relação à área de referência. Neste sentido, o Nmic mostrou-se sensível às práticas de manejo realizadas nas áreas orgânicas, anteriormente não-perceptíveis pelos estoques totais de $\mathrm{N}$.

O conteúdo de Cmic na área de pastagem foi superior $(\mathrm{P}<0,01)$ em relação às áreas sob cultivo orgânico na camada de 5-15 cm (Quadro 4, C5). A maior proporção Cmic/COT no sistema PAST em relação às áreas de cultivo revela maior conversão de $\mathrm{C}$ orgânico em $\mathrm{C}$ microbiano. Este fato indica o aumento de nutrientes na área de pastagem por meio da biomassa microbiana, a qual apresenta rápido tempo de ciclagem no solo. No entanto, o sistema pastagem o solo apresentou menor conteúdo de Nmic na camada de 0-5 cm (Quadro 4). Desta forma, as proporções Nmic/NT nas áreas orgânicas indicam que houve maior imobilização de $\mathrm{N}$ na biomassa microbiana em comparação à área de pastagem. Nas áreas orgânicas, o composto adicionado contém $2,2 \mathrm{~g} \mathrm{~kg}^{-1}$ de $\mathrm{N}$ na sua composição e relação $\mathrm{C} / \mathrm{N}$ igual a 10 (Quadro 2), o que favoreceu, provavelmente, a maior imobilização de $\mathrm{N}$ na biomassa microbiana. A maior quantidade de Nmic nas áreas de cultivo é um aspecto de grande relevância quanto à ciclagem de $\mathrm{N}$ pela biomassa microbiana. O N imobilizado pelos microrganismos 
Quadro 4. Médias dos teores e estoques de carbono e nitrogênio totais (COT e NT), microbiano (Cmic e Nmic), proporções do carbono e nitrogênio microbiano nos teores totais de carbono e nitrogênio (Cmic/COT e Nmic/NT), respiração basal (mg CO $\left.\mathrm{kg}^{-1} \mathrm{dia}^{-1}\right)$ e quociente metabólico $\left(\mathrm{qCO}_{2}\right) \mathrm{em}$ solos sob sistemas agrícolas (orgânico e convencional) e em áreas sob mata nativa nas profundidades de 0-5 e $5-15 \mathrm{~cm}$

\begin{tabular}{|c|c|c|c|c|c|c|c|c|c|c|}
\hline $\begin{array}{l}\text { Sistema/ } \\
\text { contraste }\end{array}$ & COT & NT & Cmic & Nmic & Cmic & Nmic & Cmic/COT & Nmic/NT & $\mathrm{C}-\mathrm{CO}_{2}$ & $\mathrm{qCO}_{2}$ \\
\hline & $\longrightarrow$ & $\mathrm{g}$ & 1 & - & $-\mathrm{t}$ & 1 & — & - & $m g \mathrm{~kg}^{-1} \mathrm{dia}^{-1}$ & $\begin{array}{c}\mathrm{mg} \mathrm{CO}_{2} \mathrm{mg}^{-1} \\
\text { Cmic dia }\end{array}$ \\
\hline & & & & & & $0-5$ & $\mathrm{~cm}$ & & & \\
\hline $\mathrm{ACC}_{\mathrm{E}}$ & 6,74 & 0,83 & 0,041 & 0,022 & 0,030 & 0,016 & 0,61 & 2,65 & 26,7 & 0,65 \\
\hline $\mathrm{ACC}_{\mathrm{L}}$ & 12,55 & 1,33 & 0,126 & 0,025 & 0,085 & 0,017 & 1,00 & 1,88 & 40,0 & 0,32 \\
\hline $\mathrm{ASC}_{\mathrm{E}}$ & 8,73 & 1,06 & 0,110 & 0,013 & 0,083 & 0,010 & 1,26 & 1,23 & 49,1 & 0,45 \\
\hline $\mathrm{ASC}_{\mathrm{L}}$ & 11,20 & 1,27 & 0,153 & 0,016 & 0,113 & 0,012 & 1,37 & 1,26 & 35,3 & 0,23 \\
\hline PAST & 10,17 & 1,07 & 0,141 & 0,011 & 0,110 & 0,008 & 1,39 & 1,03 & 63,1 & 0,45 \\
\hline MNo & 9,81 & 0,94 & 0,099 & 0,002 & 0,075 & 0,002 & 1,01 & 0,21 & 43,2 & 0,44 \\
\hline $\mathrm{SCC}$ & 8,34 & 0,89 & 0,092 & 0,016 & 0,072 & 0,013 & 1,10 & 1,80 & 29,1 & 0,32 \\
\hline \multirow[t]{2}{*}{$\mathrm{MNc}$} & 12,34 & 1,43 & 0,252 & 0,018 & 0,178 & 0,012 & 2,04 & 1,26 & 43,0 & 0,17 \\
\hline & \multicolumn{10}{|c|}{ Contraste ortogonal } \\
\hline $\mathrm{C} 1$ & $\mathrm{~ns}$ & $\mathrm{~ns}$ & $\mathrm{~ns}$ & $\mathrm{~ns}$ & $\mathrm{~ns}$ & $\mathrm{~ns}$ & $\mathrm{~ns}$ & $* *$ & * & \\
\hline $\mathrm{C} 2$ & $\mathrm{~ns}$ & $\mathrm{~ns}$ & $\mathrm{~ns}$ & $\mathrm{~ns}$ & $\mathrm{~ns}$ & $\mathrm{~ns}$ & $\mathrm{~ns}$ & $\mathrm{~ns}$ & $\mathrm{~ns}$ & \\
\hline C3 & $*$ & $*$ & $*$ & $\mathrm{~ns}$ & $\mathrm{~ns}$ & $\mathrm{~ns}$ & $\mathrm{~ns}$ & $\mathrm{~ns}$ & $\mathrm{~ns}$ & \\
\hline $\mathrm{C} 4$ & $\mathrm{~ns}$ & $\mathrm{~ns}$ & $\mathrm{~ns}$ & $* *$ & $\mathrm{~ns}$ & $* *$ & $\mathrm{~ns}$ & $* *$ & $\mathrm{~ns}$ & \\
\hline C5 & $\mathrm{ns}$ & $\mathrm{ns}$ & $\mathrm{ns}$ & $*$ & $\mathrm{~ns}$ & $\mathrm{~ns}$ & $\mathrm{~ns}$ & $*$ & $* *$ & \\
\hline C6 & $\mathrm{ns}$ & $\mathrm{ns}$ & $\mathrm{ns}$ & $\mathrm{ns}$ & $\mathrm{ns}$ & $\mathrm{ns}$ & $\mathrm{ns}$ & $\mathrm{ns}$ & * & \\
\hline \multirow[t]{2}{*}{$\mathrm{C} 7$} & $\mathrm{~ns}$ & $\mathrm{~ns}$ & $*$ & ns & $*$ & ns & $\mathrm{ns}$ & $*$ & $\mathrm{~ns}$ & \\
\hline & \multicolumn{10}{|c|}{$5-15 \mathrm{~cm}$} \\
\hline $\mathrm{ACC}_{\mathrm{E}}$ & 5,66 & 0,55 & 0,038 & 0,014 & 0,061 & 0,022 & 0,67 & 2,55 & 15,0 & 0,39 \\
\hline $\mathrm{ACC}_{\mathrm{L}}$ & 6,25 & 0,65 & 0,086 & 0,005 & 0,132 & 0,008 & 1,38 & 0,77 & 16,2 & 0,19 \\
\hline $\mathrm{ASC}_{\mathrm{E}}$ & 5,94 & 0,73 & 0,047 & 0,005 & 0,078 & 0,009 & 0,79 & 0,68 & 25,7 & 0,55 \\
\hline $\mathrm{ASC}_{\mathrm{L}}$ & 4,31 & 0,59 & 0,040 & 0,007 & 0,058 & 0,012 & 0,93 & 1,19 & 18,8 & 0,47 \\
\hline PAST & 7,86 & 0,83 & 0,157 & 0,004 & 0,252 & 0,007 & 2,00 & 0,48 & 35,7 & 0,23 \\
\hline MNo & 6,35 & 0,64 & 0,026 & 0,004 & 0,041 & 0,006 & 0,41 & 0,63 & 26,8 & 1,03 \\
\hline $\mathrm{SCC}$ & 7,65 & 0,77 & 0,084 & 0,010 & 0,145 & 0,018 & 1,10 & 1,30 & 24,9 & 0,30 \\
\hline \multirow[t]{2}{*}{$\mathrm{MNc}$} & 7,21 & 0,66 & 0,201 & 0,006 & 0,311 & 0,009 & 2,79 & 0,91 & 26,8 & 0,13 \\
\hline & \multicolumn{10}{|c|}{ Contraste ortogonal } \\
\hline $\mathrm{C} 1$ & $\mathrm{~ns}$ & $\mathrm{~ns}$ & $\mathrm{~ns}$ & * & $\mathrm{ns}$ & * & $\mathrm{ns}$ & * & $* *$ & \\
\hline $\mathrm{C} 2$ & $\mathrm{~ns}$ & $\mathrm{~ns}$ & $\mathrm{~ns}$ & $\mathrm{~ns}$ & $\mathrm{~ns}$ & $\mathrm{~ns}$ & $\mathrm{~ns}$ & $\mathrm{~ns}$ & $\mathrm{~ns}$ & \\
\hline $\mathrm{C} 3$ & $\mathrm{~ns}$ & $\mathrm{~ns}$ & $\mathrm{~ns}$ & $\mathrm{~ns}$ & $\mathrm{~ns}$ & ns & $\mathrm{ns}$ & $\mathrm{ns}$ & $\mathrm{ns}$ & \\
\hline $\mathrm{C} 4$ & $\mathrm{~ns}$ & $\mathrm{~ns}$ & $\mathrm{~ns}$ & $\mathrm{~ns}$ & $\mathrm{~ns}$ & $\mathrm{~ns}$ & $\mathrm{~ns}$ & $\mathrm{~ns}$ & $* *$ & \\
\hline C5 & $* *$ & $*$ & $* *$ & $\mathrm{~ns}$ & $* *$ & $\mathrm{~ns}$ & $*$ & $\mathrm{~ns}$ & $* *$ & \\
\hline C6 & $\mathrm{ns}$ & $\mathrm{ns}$ & $* *$ & $\mathrm{~ns}$ & $* *$ & $\mathrm{~ns}$ & $*$ & $\mathrm{~ns}$ & $* *$ & \\
\hline $\mathrm{C} 7$ & $\mathrm{~ns}$ & $\mathrm{~ns}$ & $*$ & $\mathrm{~ns}$ & $*$ & $\mathrm{~ns}$ & $*$ & $\mathrm{~ns}$ & $\mathrm{~ns}$ & \\
\hline
\end{tabular}

$\mathrm{ACC}_{\mathrm{E}}$ : área de acerola com coquetel com coleta de solo na entrelinha; $\mathrm{ACC}_{\mathrm{L}}$ : área de acerola com coquetel com coleta de solo na linha; $\mathrm{ASC}_{\mathrm{E}}$ : área de acerola sem coquetel com coleta de solo na entrelinha; $\mathrm{ASC}_{\mathrm{L}}$ : área de acerola sem coquetel com coleta de solo na linha; PAST: pastagem; MNo: área mata nativa referente às áreas orgânicas com acerola e pastagem; SCC: sistema de cultivo convencional; MNc: área de mata nativa referente ao sistema de cultivo convencional. $\mathrm{C} 1=\left(\mathrm{ACC}_{\mathrm{E}}-\mathrm{ASC}_{\mathrm{E}}\right) ; \mathrm{C} 2=\left(\mathrm{ACC}_{\mathrm{L}}-\mathrm{ASC}_{\mathrm{L}}\right) ; \mathrm{C}_{3}=\left(\mathrm{ACC}_{\mathrm{E}}\right.$ $\left.+\mathrm{ASC}_{\mathrm{E}}\right)-\left(\mathrm{ACC}_{\mathrm{L}}+\mathrm{ASC}_{\mathrm{L}}\right) ; \mathrm{C} 4=\left(\mathrm{ACC}_{\mathrm{E}}+\mathrm{ACC}_{\mathrm{L}}+\mathrm{ASC}_{\mathrm{E}}+\mathrm{ASC}_{\mathrm{L}}-4 \mathrm{MNo}\right) ; \mathrm{C} 5=\left(\mathrm{ACC}_{\mathrm{E}}+\mathrm{ACC}_{\mathrm{L}}+\mathrm{ASC}_{\mathrm{E}}+\mathrm{ASC}_{\mathrm{L}}-4 \mathrm{PAST}\right) ; \mathrm{C} 6=(\mathrm{PAST}$ $-\mathrm{MNo}) ; \mathrm{C} 7=(\mathrm{SCC}-\mathrm{MNc})$. ns, *, ** : não-significativos, significativos a 5 e $1 \%$, respectivamente, pelo teste $\mathrm{F}$.

será disponibilizado para as plantas em curto e médio prazo, de acordo com a ciclagem desse compartimento (Souza \& Melo, 2000).

Os teores e estoques de Cmic na PAST foram superiores aos observados no solo sob mata nativa (MNo) na profundidade de 5-15 cm (Quadro 4, C6). Os resultados do balanço de $\mathrm{C}$ obtidos pelo cálculo das diferenças nos estoques de Cmic mostraram que houve acúmulo de $211 \mathrm{~kg} \mathrm{ha}^{-1}$ no estoque de Cmic na PAST em relação à MNo (41 kg ha-1) nessa profundidade (Quadro 4), representando um incremento de $514,6 \%$ no estoque de Cmic em relação à mata nativa. Este resultado mostra que o período de pousio associado ao manejo com 
pastagem proporcionou a recuperação da biomassa microbiana no solo nesta área, principalmente em subsuperfície, o que pode estar relacionado com o efeito do sistema radicular das gramíneas em disponibilizar composto orgânicos de fácil degradação, utilizados como fonte de energia no crescimento microbiano (Freixo et al., 2002).

Os teores de Cmic obtidos no SCC foram menores em relação aos teores observados na mata nativa (MNc), nas duas profundidades avaliadas (Quadro 4, C7). Os estoques de Cmic no SCC sofreram reduções de 59 e $53 \%$, nas camadas de $0-5$ e de $5-15 \mathrm{~cm}$, respectivamente, em relação à MNc. Tais reduções foram proporcionalmente superiores àquelas observadas pelos estoques de COT. Neste sentido, confirma-se o Cmic como uma medida mais sensível às perdas de matéria orgânica relacionadas com o manejo. Os maiores valores da proporção $\mathrm{Cmic/}$ COT, observados na MNc em comparação com o SCC, indicam a maior conversão do C orgânico em C microbiano, revelando maior condição de equilíbrio no ambiente natural. Resultados semelhantes foram observados por Marchiori Júnior \& Melo (1999) e Leite et al. (2003). O revolvimento associado às maiores flutuações nos ciclos de umedecimento e secagem do solo no sistema convencional, típicos de um solo irrigado, são alguns fatores que podem ter influenciado a redução da biomassa microbiana do solo.

A produção de $\mathrm{C}-\mathrm{CO}_{2}$ na $\mathrm{PAST}$ foi superior à obtida nos sistemas de cultivo orgânico e na mata nativa (Quadro 4, C5 e C6), revelando a maior atividade da biomassa microbiana neste sistema em relação aos demais. A maior quantidade de $\mathrm{C}$ potencialmente mineralizável na pastagem implicará também maior ciclagem de $\mathrm{C}$ e nutrientes em relação aos sistemas de cultivo. Tal resultado está relacionado com a intensa ciclagem de raízes no sistema sob pastagem (D’Andréa et al., 2002).

Os dados do $\mathrm{C}-\mathrm{CO}_{2}$ relativo ao COT ajustaramse ao modelo linear em todos os sistemas de manejo avaliados (Figura 1). O maior coeficiente angular da reta na área de pastagem indica que o sistema PAST liberou maior quantidade de $\mathrm{C}-\mathrm{CO}_{2}$ em relação aos demais sistemas, confirmando a maior atividade microbiana nesta área. Comportamento semelhante foi observado por Balota et al. (1998).

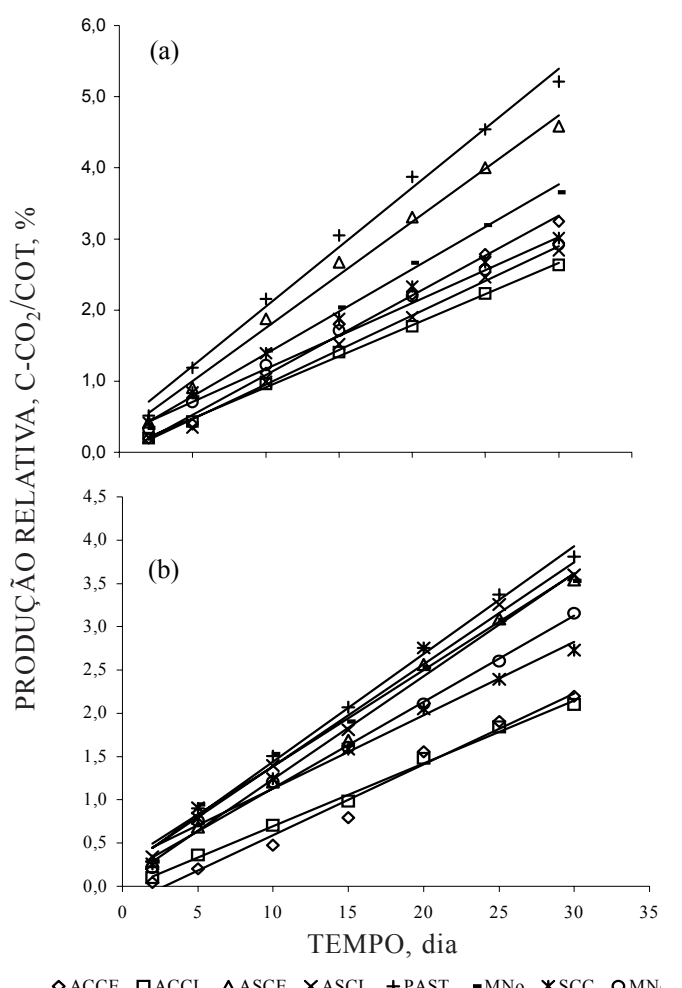

$$
\begin{aligned}
& \hat{Y}_{\mathrm{ACC}_{\mathrm{E}}}=-0,0328+0,112 \mathrm{x}\left(\mathrm{R}^{2}=0,99^{* *}\right) \\
& \hat{Y}_{\mathrm{ACC}_{\mathrm{L}}}=0,0409+0,0873 \mathrm{x}\left(\mathrm{R}^{2}=0,99^{* *}\right) \\
& \hat{Y}_{\mathrm{ASC}_{\mathrm{E}}}=0,2542+0,1495 \mathrm{x}\left(\mathrm{R}^{2}=0,99^{* *}\right) \\
& \hat{Y}_{\mathrm{ASC}_{\mathrm{L}}}=-0,022+0,0973 \mathrm{x}\left(\mathrm{R}^{2}=0,99^{* *}\right) \\
& \hat{Y}_{\mathrm{PAST}}=0,3751+0,1674 \mathrm{x}\left(\mathrm{R}^{2}=0,99^{* *}\right) \\
& \hat{Y}_{\mathrm{MNo}}=0,1923+0,1191 \mathrm{x}\left(\mathrm{R}^{2}=0,99^{* *}\right) \\
& \hat{Y}_{S C C}=0,3851+0,0920 \mathrm{x}\left(\mathrm{R}^{2}=0,99^{* *}\right) \\
& \hat{Y}_{\mathrm{MNc}}=0,2439+0,0929 \mathrm{x}\left(\mathrm{R}^{2}=0,99^{* *}\right) \\
& \hat{Y}_{\mathrm{ACC}}=-0,2291+0,082 \mathrm{x}\left(\mathrm{R}^{2}=0,98^{* *}\right) \\
& \hat{Y}_{\mathrm{ACC}}=-0,0284+0,0725 \mathrm{x}\left(\mathrm{R}^{2}=0,99^{* *}\right) \\
& \hat{Y}_{\mathrm{ASC}}=0,0461+0,119 \mathrm{x}\left(\mathrm{R}^{2}=0,99^{* *}\right) \\
& \hat{Y}_{\mathrm{ASC}}=0,2093+0,1178 \mathrm{x}\left(\mathrm{R}^{2}=0,99^{* *}\right) \\
& \hat{Y}_{\mathrm{PAST}_{\mathrm{L}}}=0,1971+0,1244 \mathrm{x}\left(\mathrm{R}^{2}=0,99^{* *}\right) \\
& \hat{Y}_{\mathrm{MNO}}=0,2714+0,1113 \mathrm{x}\left(\mathrm{R}^{2}=0,99^{* *}\right) \\
& \hat{Y}_{\mathrm{SCC}}=0,2836+0,0848 \mathrm{x}\left(\mathrm{R}^{2}=0,98^{* *}\right) \\
& \hat{Y}_{\mathrm{MNc}}=0,1396+0,0997 \mathrm{x}\left(\mathrm{R}^{2}=0,99^{* *}\right)
\end{aligned}
$$

$\diamond \mathrm{ACCE} \square \mathrm{ACCL} \triangle \mathrm{ASCE} \times \mathrm{ASCL}+\mathrm{PAST}-\mathrm{MNO} * \mathrm{SCC}$ OMN

Figura 1. Produção relativa acumulada de $\mathrm{C}-\mathrm{CO}_{2}$ em relação do conteúdo de carbono orgânico total em função do tempo de incubação em sistemas agrícolas (orgânico e convencional) e em áreas sob mata nativa nas camadas de 0-5 cm (A) e de 5-15 cm (B). ACC $_{\mathrm{E}}$ : área de acerola com coquetel com coleta de solo na entrelinha; $\mathrm{ACC}_{\mathrm{L}}$ : área de acerola com coquetel com coleta de solo na linha; $\mathrm{ASC}_{\mathrm{E}}$ : área de acerola sem coquetel com coleta de solo na entrelinha; $\mathrm{ASC}_{\mathrm{L}}$ : área de acerola sem coquetel com coleta de solo na linha; PAST: pastagem; MNo: área de mata nativa referente às áreas orgânicas com acerola e pastagem; SCC: sistema de cultivo convencional; MNc: área de mata nativa referente ao sistema de cultivo convencional. 
De modo geral, as curvas que relacionam a produção acumulada de $\mathrm{C}-\mathrm{CO}_{2}$ de acordo com o tempo de incubação do solo ajustam-se ao modelo exponencial, permitindo a visualização de dois estádios distintos (Corea, 1998; Medeiros, 1999). O primeiro estádio indica a utilização da porção lábil do $\mathrm{C}$ presente no solo pelos microrganismos, representado pela parte linear da reta. O segundo, representado pela parte menos inclinada da curva, indica a utilização do $\mathrm{C}$ de menor labilidade. No presente estudo, não foi verificado o segundo estádio da curva de regressão para todos os sistemas de manejo avaliados (Figura 1). É provável que o ajuste da regressão no modelo exponencial fosse obtido, se houvesse maior tempo de incubação do solo.

De modo geral, na camada de $0-5 \mathrm{~cm}$, os valores do quociente metabólico $\left(\mathrm{qCO}_{2}\right)$ nos sistemas orgânicos estiveram abaixo do valor obtido na mata nativa (MNo), principalmente os valores obtidos nas linhas, o que demonstra o acúmulo de $\mathrm{C}$ nas áreas cultivadas (Quadro 4). O valor de $\mathrm{qCO}_{2}$ observado na pastagem foi semelhante ao obtido na mata nativa na mesma profundidade. Já o SCC apresentou maior valor de $\mathrm{qCO}_{2}$ em relação à $\mathrm{MNc}$ na camada superficial, indicando a influência negativa das práticas de manejo na área cultivada, decorrente do estresse na biomassa microbiana do solo nesse sistema (Tótola \& Chaer, 2002). Segundo os resultados, o $\mathrm{qCO}_{2}$ foi um bom indicador das mudanças nos teores de matéria orgânica, considerando o manejo do solo.

\section{Matéria orgânica leve}

A matéria orgânica leve (MOL) é constituída por resíduos orgânicos parcialmente humificados em vários estádios de decomposição e apresenta um tempo de residência no solo que varia de 1 a 5 anos (Janzen et al., 1992). Esta fração pode ser quantificada por meio de flotação do material em líquido de densidade variando de 1,6 a $2,0 \mathrm{~kg} \mathrm{~L}^{-1}$ (Sohi et al., 2001).

Os teores de MOL não foram influenciados pelos sistemas de manejo na camada de $0-5 \mathrm{~cm}$ (Quadro 5). Observou-se a tendência de os conteúdos de MOL nas linhas superarem os obtidos nas entrelinhas da camada superficial dos sistemas orgânicos. Certamente, a influência do manejo por meio do maior aporte de matéria orgânica favoreceu a maior quantidade de MOL nas linhas. De modo semelhante, o teor de C presente na MOL (Cmol) nas linhas foi, aproximadamente, duas vezes maior que o teor obtido nas entrelinhas. O acúmulo de MOL nas linhas apresentará maior fornecimento de substrato utilizado como fonte de energia para o crescimento microbiano, o que poderá levar à liberação de nutrientes por meio da ciclagem da biomassa microbiana, além de favorecer a recuperação do equilíbrio biológico do solo e de sua qualidade (Marin, 2002).
Já na camada de $5-15 \mathrm{~cm}$, observou-se que o conteúdo de MOL foi superior nas entrelinhas entre as áreas de cultivo com acerola (Quadro 5, C3). Esta constatação evidencia que o efeito da adubação orgânica realizada na área, em relação ao incremento de MOL, restringe-se somente aos primeiros centímetros de solo, enquanto, nas entrelinhas, este efeito parece ser mais favorecido pela reciclagem da biomassa vegetal proveniente das plantas espontâneas.

Os estoques de $\mathrm{Cmol}$, obtidos nas linhas de cultivo nos sistemas $\mathrm{ACC}_{\mathrm{L}}$ e $\mathrm{ASC}_{\mathrm{L}}$, apresentaram incrementos de 2,6 e 2,4 t ha ${ }^{-1}$, respectivamente, em relação à mata nativa na camada de $0-5 \mathrm{~cm}$ (Quadro 5), o que significa um aumento em $111 \mathrm{e}$ $104 \%$, respectivamente, nos estoques de MOL nas áreas cultivadas em relação ao ambiente natural.

A área de pastagem não diferiu das áreas de cultivo quanto aos teores de Cmol; no entanto, apresentou teores e estoques de $\mathrm{Nmol}$ superiores $(\mathrm{P}<0,05)$ na camada de 5-15 cm (Quadro 5, C5).

Observou-se tendência de redução no estoque de Cmol no $\mathrm{SCC}$ em relação à MNc na camada superficial (Quadro 5). As perdas de Cmol em superfície nos solos sob o sistema de cultivo convencional provavelmente estão associadas tanto ao revolvimento do solo, que aumenta as taxas de oxidação da matéria orgânica, como a retirada dos restos culturais. Já em subsuperfície, a tendência de estoques semelhantes de Cmol no sistema convencional, em relação à mata nativa, pode estar associada à mobilização de resíduos orgânicos para as camadas inferiores provocada pela ação dos implementos agrícolas durante o do preparo do solo.

Dentre os compartimentos da matéria orgânica do solo, a MOL pode ser considerada como compartimento lento dentro da dinâmica do $\mathrm{C}$ e N no solo (Leite, 2002). A manutenção desse compartimento, portanto, torna-se fundamental para a sustentabilidade dos sistemas agrícolas, uma vez que este representa, em curto e médio prazo, potencial para ciclagem de nutrientes (Compton \& Boone, 2002). Os resultados obtidos revelaram que os sistemas de cultivo orgânico continham maiores conteúdos de MOL em relação à mata nativa, que é a condição de referência. Este fato aponta para a recuperação do solo nas áreas cultivadas em bases orgânicas.

A proporção $\mathrm{Cmol} / \mathrm{COT}$ indicou que o $\mathrm{Cmol}$ entre os sistemas de cultivo orgânico representou de 26 a $59 \%$ do COT, na profundidade de $0-5 \mathrm{~cm}$, e de 15 a $25 \%$ do COT, na profundidade de $5-15 \mathrm{~cm}$ (Quadro 5). Percebe-se que os valores desta proporção nos sistemas orgânicos estão muito acima dos obtidos por outros pesquisadores (Gijsman, 1996; Leite et al., 2003), os quais obtiveram valores dessa mesma proporção variando de 6 a $13 \%$ nas camadas 
Quadro 5. Médias dos teores e estoques de matéria orgânica leve (MOL), carbono e nitrogênio da matéria orgânica leve ( $\mathrm{Cmol}$ e $\mathrm{Nmol}$ ) e proporções entre carbono da matéria orgânica leve com carbono orgânico total (Cmol/COT), nitrogênio da matéria orgânica leve com nitrogênio total (Nmol/NT), carbono da biomassa microbiana com carbono da matéria orgânica leve (Cmic/Cmol) e nitrogênio da biomassa microbiana com nitrogênio da matéria orgânica leve ( $\mathrm{Nmic/Nmol)} \mathrm{em} \mathrm{solos} \mathrm{sob} \mathrm{sistemas}$ agrícolas (orgânico e convencional) e em áreas sob mata nativa nas profundidades de 0-5 e 5-15 cm

\begin{tabular}{|c|c|c|c|c|c|c|c|c|c|}
\hline $\begin{array}{c}\text { Sistema/ } \\
\text { contrastes }\end{array}$ & MOL & Cmol & Nmol & Cmol & Nmol & $\mathrm{Cmol} / \mathrm{COT}$ & Nmol/NT & Cmic/Cmol & Nmic/Nmol \\
\hline & 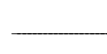 & $\mathrm{g} \mathrm{kg}^{-1}$ & - & $-\mathrm{t}$ & 1 & 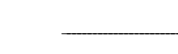 & $\%$ & 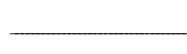 & 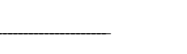 \\
\hline & \multicolumn{9}{|c|}{$0-5 \mathrm{~cm}$} \\
\hline $\mathrm{ACC}_{\mathrm{E}}$ & 25,42 & 2,52 & 0,08 & 1,81 & 0,06 & 37,4 & 9,6 & 1,6 & 27,5 \\
\hline $\mathrm{ACC}_{\mathrm{L}}$ & 33,78 & 6,96 & 0,24 & 4,95 & 0,17 & 55,5 & 18,0 & 1,8 & 10,4 \\
\hline $\mathrm{ASC}_{\mathrm{E}}$ & 23,79 & 3,82 & 0,17 & 2,87 & 0,13 & 43,8 & 16,0 & 2,9 & 7,6 \\
\hline $\mathrm{ASC}_{\mathrm{L}}$ & 36,53 & 6,58 & 0,30 & 4,79 & 0,22 & 58,8 & 23,6 & 2,3 & 5,3 \\
\hline PAST & 22,98 & 3,68 & 0,19 & 2,80 & 0,14 & 36,2 & 17,8 & 3,8 & 5,8 \\
\hline $\mathrm{MNo}$ & 15,55 & 3,20 & 0,20 & 2,35 & 0,15 & 32,6 & 21,3 & 3,1 & 1,0 \\
\hline $\mathrm{SCC}$ & 11,76 & 2,22 & 0,10 & 1,72 & 0,07 & 26,6 & 11,2 & 4,1 & 16,0 \\
\hline \multirow[t]{2}{*}{$\mathrm{MNc}$} & 15,62 & 3,53 & 0,15 & 2,49 & 0,11 & 28,6 & 10,5 & 7,1 & 12,0 \\
\hline & \multicolumn{9}{|c|}{ Contraste ortogonal } \\
\hline $\mathrm{C} 1$ & $\mathrm{~ns}$ & $\mathrm{~ns}$ & $\mathrm{~ns}$ & $\mathrm{~ns}$ & $\mathrm{~ns}$ & $\mathrm{~ns}$ & ns & ns & $\mathrm{ns}$ \\
\hline $\mathrm{C} 2$ & $\mathrm{~ns}$ & $\mathrm{~ns}$ & $\mathrm{~ns}$ & $\mathrm{~ns}$ & ns & $\mathrm{ns}$ & ns & $\mathrm{ns}$ & $\mathrm{ns}$ \\
\hline $\mathrm{C} 3$ & $\mathrm{~ns}$ & $\mathrm{~ns}$ & $\mathrm{~ns}$ & $\mathrm{~ns}$ & $\mathrm{~ns}$ & $\mathrm{~ns}$ & ns & ns & $\mathrm{ns}$ \\
\hline $\mathrm{C} 4$ & $\mathrm{~ns}$ & $\mathrm{~ns}$ & $\mathrm{~ns}$ & $\mathrm{~ns}$ & $\mathrm{~ns}$ & $\mathrm{~ns}$ & $\mathrm{~ns}$ & $\mathrm{~ns}$ & $\mathrm{~ns}$ \\
\hline C5 & $\mathrm{ns}$ & $\mathrm{ns}$ & $\mathrm{ns}$ & ns & $\mathrm{ns}$ & ns & $\mathrm{ns}$ & ns & $\mathrm{ns}$ \\
\hline C6 & $\mathrm{ns}$ & $\mathrm{ns}$ & $\mathrm{ns}$ & $\mathrm{ns}$ & $\mathrm{ns}$ & $\mathrm{ns}$ & ns & ns & $\mathrm{ns}$ \\
\hline \multirow[t]{2}{*}{$\mathrm{C} 7$} & $\mathrm{~ns}$ & $\mathrm{~ns}$ & $\mathrm{~ns}$ & $\mathrm{~ns}$ & $\mathrm{~ns}$ & $\mathrm{~ns}$ & $\mathrm{~ns}$ & ns & $\mathrm{ns}$ \\
\hline & \multicolumn{9}{|c|}{$5-15 \mathrm{~cm}$} \\
\hline $\mathrm{ACC}_{\mathrm{E}}$ & 9,66 & 1,11 & 0,01 & 1,77 & 0,02 & 19,6 & 1,8 & 3,4 & 140,0 \\
\hline $\mathrm{ACC}_{\mathrm{L}}$ & 5,86 & 0,93 & 0,03 & 1,42 & 0,05 & 14,9 & 4,6 & 9,2 & 16,7 \\
\hline $\mathrm{ASC}_{\mathrm{E}}$ & 8,03 & 1,50 & 0,08 & 2,47 & 0,13 & 25,3 & 11,0 & 3,1 & 6,3 \\
\hline $\mathrm{ASC}_{\mathrm{L}}$ & 6,82 & 0,99 & 0,04 & 1,46 & 0,06 & 23,0 & 6,8 & 4,0 & 17,5 \\
\hline PAST & 7,02 & 1,44 & 0,08 & 2,32 & 0,13 & 18,3 & 9,6 & 10,9 & 5,0 \\
\hline $\mathrm{MNo}$ & 5,57 & 0,97 & 0,06 & 1,52 & 0,10 & 15,3 & 9,4 & 2,7 & 6,7 \\
\hline $\mathrm{SCC}$ & 8,11 & 1,20 & 0,04 & 2,05 & 0,07 & 15,7 & 5,2 & 7,0 & 25,0 \\
\hline \multirow[t]{2}{*}{$\mathrm{MNc}$} & 6,03 & 1,28 & 0,04 & 1,99 & 0,07 & 17,8 & 6,1 & 15,7 & 15,0 \\
\hline & \multicolumn{9}{|c|}{ Contraste ortogonal } \\
\hline $\mathrm{C} 1$ & $\mathrm{~ns}$ & $\mathrm{~ns}$ & $* *$ & $\mathrm{~ns}$ & $* *$ & $\mathrm{~ns}$ & $* *$ & $\mathrm{~ns}$ & $\mathrm{~ns}$ \\
\hline $\mathrm{C} 2$ & $\mathrm{~ns}$ & $\mathrm{~ns}$ & $\mathrm{~ns}$ & ns & ns & ns & $\mathrm{ns}$ & ns & $\mathrm{ns}$ \\
\hline $\mathrm{C} 3$ & $*$ & $\mathrm{~ns}$ & $\mathrm{~ns}$ & $\mathrm{~ns}$ & ns & $\mathrm{ns}$ & $\mathrm{ns}$ & $\mathrm{ns}$ & $\mathrm{ns}$ \\
\hline $\mathrm{C} 4$ & $\mathrm{~ns}$ & $\mathrm{~ns}$ & $*$ & $\mathrm{~ns}$ & $*$ & ns & $* *$ & $\mathrm{~ns}$ & $\mathrm{~ns}$ \\
\hline C5 & ns & $\mathrm{ns}$ & * & ns & $*$ & ns & $* *$ & ns & $\mathrm{ns}$ \\
\hline $\mathrm{C} 6$ & $\mathrm{~ns}$ & $\mathrm{~ns}$ & $\mathrm{~ns}$ & $\mathrm{~ns}$ & $\mathrm{~ns}$ & ns & $\mathrm{ns}$ & $*$ & $\mathrm{~ns}$ \\
\hline $\mathrm{C} 7$ & $\mathrm{~ns}$ & $\mathrm{~ns}$ & $\mathrm{~ns}$ & ns & $\mathrm{ns}$ & $\mathrm{ns}$ & $\mathrm{ns}$ & $* *$ & $\mathrm{~ns}$ \\
\hline
\end{tabular}

$\overline{\mathrm{ACC}_{\mathrm{E}}}$ : área de acerola com coquetel com coleta de solo na entrelinha; $\mathrm{ACC}_{\mathrm{L}}$ : área de acerola com coquetel com coleta de solo na linha; $\mathrm{ASC}_{\mathrm{E}}$ : área de acerola sem coquetel com coleta de solo na entrelinha; $\mathrm{ASC}_{\mathrm{L}}$ : área de acerola sem coquetel com coleta de solo na linha; PAST: pastagem; MNo: área mata nativa referente às áreas orgânicas com acerola e pastagem; SCC: sistema de cultivo convencional; MNc: área de mata nativa referente ao sistema de cultivo convencional. $\mathrm{C} 1=\left(\mathrm{ACC}_{\mathrm{E}}-\mathrm{ASC}_{\mathrm{E}}\right) ; \mathrm{C} 2=\left(\mathrm{ACC}_{\mathrm{L}}-\mathrm{ASC}_{\mathrm{L}}\right) ; \mathrm{C}_{3}=\left(\mathrm{ACC}_{\mathrm{E}}\right.$ $\left.+\mathrm{ASC}_{\mathrm{E}}\right)-\left(\mathrm{ACC}_{\mathrm{L}}+\mathrm{ASC}_{\mathrm{L}}\right) ; \mathrm{C} 4=\left(\mathrm{ACC}_{\mathrm{E}}+\mathrm{ACC}_{\mathrm{L}}+\mathrm{ASC}_{\mathrm{E}}+\mathrm{ASC}_{\mathrm{L}}-4 \mathrm{MNo}\right) ; \mathrm{C} 5=\left(\mathrm{ACC}_{\mathrm{E}}+\mathrm{ACC}_{\mathrm{L}}+\mathrm{ASC}_{\mathrm{E}}+\mathrm{ASC}_{\mathrm{L}}-4 \mathrm{PAST}\right) ; \mathrm{C} 6=(\mathrm{PAST}$ $-\mathrm{MNo}) ; \mathrm{C} 7=(\mathrm{SCC}-\mathrm{MNc})$. ns, ${ }^{*},{ }^{* *}$ : não-significativo, significativos a 5 e $1 \%$, respectivamente, pelo teste $\mathrm{F}$.

superficiais do solo. Janzen et al. (1992) destacaram que, sob condições relativamente áridas, a MOL tende a decompor-se a taxas lentas e acumular-se em teores elevados em comparação com condições de maior umidade. Este comportamento está associado, principalmente, à redução da atividade microbiana. Desta forma, acredita-se que a MOL no ambiente do presente estudo não esteja somente associada à 
adição de resíduos orgânicos, mas também ao acúmulo destes, graças à baixa atividade da biomassa microbiana.

Os valores das proporções $\mathrm{Cmic} / \mathrm{Cmol}$ e Nmic/ $\mathrm{Nmol}$ indicam o percentual de $\mathrm{C}$ e $\mathrm{N}$ da $\mathrm{MOL}$ que está sendo convertido em biomassa microbiana. Nos sistemas orgânicos, na profundidade de $0-5 \mathrm{~cm}$, os valores da relação $\mathrm{Cmic/Cmol} \mathrm{nas} \mathrm{áreas} \mathrm{de}$ incorporação de coquetel $\left(\mathrm{ACC}_{\mathrm{E}}\right.$ e $\left.\mathrm{ACC}_{\mathrm{L}}\right)$ foram menores em comparação àqueles observados nas áreas não incorporadas $\left(\mathrm{ASC}_{\mathrm{E}}\right.$ e $\left.\mathrm{ASC}_{\mathrm{L}}\right)$ (Quadro 5). Por outro lado, nas mesmas áreas, a proporção Nmicl Nmol foi maior nas áreas de incorporação, indicando que o manejo realizado favoreceu maior conversão de Nmol em tecido microbiano em comparação ao $\mathrm{Cmol}$, podendo acarretar maior reciclagem de $\mathrm{N}$ nesse ambiente pela ação da biomassa microbiana.

$\mathrm{Na}$ área de pastagem, observaram-se maiores valores da proporção $\mathrm{Cmic/Cmol} \mathrm{em} \mathrm{comparação} \mathrm{às}$ áreas de cultivo orgânico nas duas profundidades (Quadro 5). É provável que nessa área tenha ocorrido maior acesso dos microrganismos à MOL, cujo efeito refletiu-se no incremento da biomassa microbiana, o que confirma os resultados de maior atividade microbiana obtidos na área de pastagem (Figura 1). Estes resultados validam a importância da MOL no fornecimento de energia para o crescimento e atividade da biomassa microbiana (Janzen et al., 1992; Leite, 2002).

O percentual da proporção $\mathrm{Cmic/Cmol} \mathrm{obtido} \mathrm{no}$ $\operatorname{SCC}(4,1 \%)$ foi menor em relação à área $\mathrm{MNc}(7,1 \%)$ na profundidade de $0-5 \mathrm{~cm}$. Por outro lado, na mesma profundidade, a proporção $\mathrm{Nmic} / \mathrm{Nmol}$ foi maior no SCC (16\%) comparativamente à $\mathrm{MNc}$ (12\%). As mesmas tendências foram observadas na profundidade de 5-15 cm (Quadro 5). Os resultados apontam para uma menor imobilização de $\mathrm{Cmol}$ diante da maior imobilização de Nmol nos tecidos microbianos no sistema convencional em relação à mata nativa. Estes resultados permitem inferir que a natureza dos resíduos orgânicos que originam a MOL nos dois ambientes é diferente, exercendo influências diferenciadas sobre a biomassa microbiana do solo.

\section{CONCLUSÕES}

1. O manejo de áreas sob cultivo orgânico com acerola e pastagem contribuiu para a manutenção e recuperação dos conteúdos de $\mathrm{C}$ e $\mathrm{N}$ da biomassa microbiana e da matéria orgânica leve, constituindo estratégias de manejo importantes a serem consideradas para a conservação e, ou, aumento da matéria orgânica e, conseqüentemente, para a melhoria da qualidade do solo e para a implementação do seqüestro de $\mathrm{C}$ na região da Chapada da Ibiapaba, Ceará.
2. Os incrementos e, ou, reduções de $\mathrm{C}$ e $\mathrm{N}$ nos compartimentos na biomassa microbiana e na matéria orgânica leve entre os sistemas de manejo, em comparação à área nativa de referência, foram proporcionalmente maiores que os valores obtidos, quando considerados somente os estoques de C orgânico e $\mathrm{N}$ totais, principalmente na área sob sistema de cultivo convencional. Isto indica que estes compartimentos podem ser considerados indicadores sensíveis às mudanças no estado da matéria orgânica de acordo com o manejo.

\section{LITERATURA CITADA}

ANDERSON, J.P.E. Soil respiration. In: PAGE, A.L.; MILLER, R.H. \& KEENEY, D.R., eds. Methods of soil analysis. Part 2. Chemical and microbiological properties. 2.ed. Madison, Soil Science Society of America/American Society of Agronomy, 1982. p.831-845.

ANDERSON, T.H. \& DOMSCH, K.H. Determination of ecophysiological maintenance carbon requirements of soil microorganisms in a dormant state. Biol. Fertil. Soils, 1:81-89, 1985 .

ARAUJO, F.S.; MARTINS, F.R. \& SHEPHERD, G.J. Variações estruturais e florísticas do carrasco no planalto da Ibiapaba, Estado do Ceará. R. Bras. Biol., 59:663-678, 1999.

BALOTA, E.L.; COLOZZI-FILHO, A.; ANDRADE, D.S. \& HUNGRIA, M. Biomassa microbiana e sua atividade em solos sob diferentes sistemas de preparo e sucessão de culturas. R. Bras. Ci. Solo, 22:641-649, 1998.

BAYER, C.; MARTIN-NETO, L.; MIELNICZUK, J. \& CERETTA, C.A. Effect of no-till cropping systems on soil organic matter in sandy clay loam acrisol from southern Brazil monitored by electron spin resonance and nuclear magnectic resonance. Soil Till. Res., 53:95-104, 2000.

BROOKES, P.C.; LANDMAN, A.; PRUDEN, G. \& JENKINSON, D.S. Chloroform furrigation and the release of soil nitrogen: A rapid direct extration method for measuring microbial biomass nitrogen in soil. Soil Biol. Biochem., 17:837-842, 1985.

COMPTON, J.E. \& BOONE, R.D. Soil nitrogen transformations and the role of light fraction organic matter in forest soils. Soil Biol. Biochem., 34:933-943, 2002 .

COREA, E.J.V. Avaliação do carbono orgânico do solo sob diferentes condições de manejo. Viçosa, Universidade Federal de Viçosa, MG, 1998. 76p. (Tese de Mestrado)

D‘ANDRÉA, A.F.; SILVA, M.L.N.; CURI, N.; SIQUEIRA, J.O. \& CARNEIRO, M.A.C. Atributos biológicos indicadores da qualidade do solo em sistemas de manejo na região do cerrado no sul do estado de Goiás. R. Bras. Ci. Solo, 26:913923, 2002 .

FERREIRA, A.S.; CAMARGO, F.A.O. \& VIDOR, C. Utilização de microondas na avaliação da biomassa microbiana do solo. R. Bras. Ci. Solo, 23:991-996, 1999. 
FREIXO, A.A.; MACHADO, P.L.O.A.; GUIMARÃES, C.M.; SILVA, C.A. \& FADIGAS, F.S. Estoques de carbono e nitrogênio e distribuição de frações orgânicas de Latossolo do cerrado sob diferentes sistemas de cultivo. R. Bras. Ci. Solo, 26:425-434, 2002.

GIJSMAN, A.J. Soil aggregate stability and soil organic matter fractions under agropastoral systems established in native savanna. Aust. J. Soil Res., 34:891-907, 1996.

ISLAM, K.R. \& WEIL, R.R. Microwave irradiation of soil for routine measurement of microbial biomass carbon. Biol. Fertil. Soils, 27:408-416, 1998.

JANZEN, H.H.; CAMPBELL, C.A.; BRANDT, S.A.; LAFOND, G.P. \& TOWNLEY-SMITH, L. Light-fraction organic matter in soils from long-term crop rotations. Soil Sci. Soc. Am. J., 56:1799-1806, 1992.

LEITE, L.F.C. Compartimentos e dinâmica da matéria orgânica do solo sob diferentes manejos e sua simulação pelo modelo Century. Viçosa, MG, Universidade Federal de Viçosa, 2002. 142p. (Tese de Doutorado)

LEITE, L.F.C.; MENDONÇA, E.S.; NEVES, J.C.L.; MACHADO, P.L.O.A. \& GALVÃO, J.C.C. Estoques totais de carbono orgânico e seus compartimentos em Argissolo sob floresta e sob milho cultivado com adubação mineral e orgânica. R. Bras. Ci. Solo, 27:821-832, 2003.

LUNDQUIST, E.J.; JACKSON, L.E.; SCOW, K.M. \& HSU, C. Changes in microbial biomass and community composition, and soil carbon and nitrogen pools after incorporation of Rye into three California agricultural soils. Soil Biol. Biochem., 31:221-236, 1999.

MARCHIORI JÚNIOR, M. \& MELO, W.J. Carbono, Carbono da biomassa microbiana e atividade enzimática em um solo sob mata natural, pastagem e cultura do algodoeiro. R. Bras. Ci. Solo, 23:257-263, 1999.

MARCHIORI JÚNIOR, M. \& MELO, W.J. Alterações na matéria orgânica e na biomassa microbiana em solo de mata natural submetido a diferentes manejos. Pesq. Agropec. Bras., 35:1177-1182, 2000.

MARIN, A.M.P. Impactos de um sistema agroflorestal com café na qualidade do solo. Viçosa, MG, Universidade Federal de Viçosa, 2002. 83p. (Tese de Mestrado)

MEDEIROS, M.L. Carbono orgânico extraído por soluções de $\mathrm{KNO}_{3} \mathrm{e} \mathrm{NaHSO}_{4}$ e sua relação com outras formas de carbono no solo. Viçosa, MG, Universidade Federal de Viçosa, 1999. 56p. (Tese de Mestrado)
MIELNICZUK, J.; BAYER, C.; BESAN, F.M.; LOVATO, T.; FERNÁNDEZ, F.F. \& DEBARBA, L. Manejo de solo e culturas e sua relação com os estoques de carbono e nitrogênio do solo. In: CURI, N.; MARQUES, J.J.; GUILHERME, L.R.G.; LIMA, J.M.; LOPES, A.S. \& ALVAREZ V., V.H., eds. Tópicos em ciência do solo. Viçosa, MG, Sociedade Brasileira de Ciência do Solo, 2003. v.3. p.209-248.

PAES, J.M.V.; ANDREOLA, F.; BRITO, C.H. \& LOUDES, E.G. Decomposição da palha de café em três tipos de solo e sua influência sobre a CTC e o pH. R. Ceres, 43:337-392, 1996.

RASMUSSEN, P.E.; ALBRECHT, S.L. \& SMILEY, R.W. Soil $\mathrm{C}$ and $\mathrm{N}$ changes under tillage and cropping systems in semi-arid pacific northwest agriculture. Soil Till. Res., 47:197-205, 1998.

SAPARLING, G.P. \& WEST, A.W. A direct extraction method to estimate soil microbial C:Calibration in situ using microbial respiration and 14C labelled cells. Soil Biol. Biochem., 20:337-343, 1988.

SILVA, J.E. \& RESCK, D.V.S. Matéria orgânica do solo. In: VARGAS, M.A.T. \& HUNGRIA, M., ed. Biologia dos solos dos cerrados. Planaltina, Embrapa-CPAC, 1997, p.467524.

SOHI, S.; MAHIEU, N.; ARAH, J.R.M.; POLWSON, D.S.P.; MADARI, B. \& GAUNT, J.L. A procedure for isolating soil organic matter fractions suitable for modeling. Soil Sci. Soc. Am. J., 65:1121-1128, 2001.

SOUZA, W.J.O. \& MELO, W.J. Teores de nitrogênio no solo e nas frações da matéria orgânica sob diferentes sistemas de produção de milho. R. Bras. Ci. Solo, 24:885-896, 2000.

TEDESCO, M.J.; GIANELLO, G.; BISSANI, C.A.; BOHNEN, H. \& VOLKWEIS, S.I. Análise de solo, plantas e outros materiais. 2.ed. Porto alegre, Universidade Federal do Rio Grande do Sul, 1995. 174p.

TÓTOLA, M.R. \& CHAER, G.M. Microrganismos e processos microbiológicos como indicadores da qualidade dos solos. In: ALVAREZ V., V.H.; SCHAEFER, C.E.G.R.; BARROS, N.F.; MELLO, J.W.V. \& COSTA, L.M., eds. Tópicos em ciência do solo. Viçosa, MG, Sociedade Brasileira de Ciência do Solo, 2002. v.2. p.196-275.

YEOMANS, J.C. \& BREMNER, J.M.. A rapid and precise method for routine determimation of organic carbon in soil. Comm. Soil. Sci. Plant Anal., 19:1467-1476, 1988. 